Research Article

\title{
To study prescription behavior of physician in regard to brand and generic name
}

\author{
Rakesh Kumar*, Jagminder Kaur Bajaj, Megha Sood, Nipunjot Grewal, Baljit Jassal
}

Department of Pharmacology, Punjab Institute of Medical Sciences, Jalandhar, Punjab, India

Received: 18 April 2016 Accepted: 03 June 2016

*Correspondence to:

Dr. Rakesh Kumar, Email: bagharakesh@ hotmail.com

Copyright: (C) the author(s), publisher and licensee Medip Academy. This is an openaccess article distributed under the terms of the Creative Commons Attribution NonCommercial License, which permits unrestricted noncommercial use, distribution, and reproduction in any medium, provided the original work is properly cited.

\begin{abstract}
Background: Drugs are the chemical substances used for diagnosis, prevention and treatment of a disease. They are prescribed either by using generic name or brand name. The objective of this study was study the preference of registered medical practitioners towards prescribing of drugs by generic name or brand name and to know the reasons for the same.

Methods: The questionnaire based observational study was done on 300 registered medical practitioners after satisfying inclusion and exclusion criteria. The data collected was evaluated and the response recorded in percentage.

Results: Out of 300 practitioners $92 \%$ admitted prescribing drug by brand name for fear of substitution by substandard product and did not allow pharmacist to substitute the same, rest $8 \%$ prescribe by generic names. $78 \%$ considered generic drugs to be less efficacious and $3 \%$ had the view that they have more side effects. $83 \%$ doctors consider patient affordability while prescribing however only $60 \%$ of them informed patients about the cost of prescribed drugs. Other factors influencing prescription behaviour were health care administration policy $(10 \%)$ and company representative $(7 \%)$.

Conclusions: Majority of physicians prescribe drugs by brand names due to its assured efficacy and they are reluctant to prescribe generic names because of their view of substitution by less efficacious, substandard and counterfeit products. The regulating agencies have to assure the efficacy of generic products. The spurious and substandard drugs available in the market have to be checked and strict action should be taken in order to maintain the quality of these products. This will boost the confidence of the physicians in prescribing the generic drugs resulting in decreased health care cost.
\end{abstract}

Keywords: Generic name, Brand name, Drug, Preference, Side effects

\section{INTRODUCTION}

Drug is a chemical substance used for the prevention, diagnosis and treatment of disease. Every drug manufactured by the pharmaceutical company has three names; a chemical name, a generic/nonproprietary/official/approved name and a brand/proprietary name. The chemical name describes the chemical compound and is difficult to remember and inconvenient to prescribe. Generic names for new compounds are given by 'United States adopted name council' and are uniform throughout the world as per the international agreement. Brand names are given by pharmaceutical companies for marketing their product. ${ }^{1}$ Drugs are prescribed by using either generic name or brand name. During practice physicians prefer brand names ignoring the fact that they are trained to prescribe by generic name during their graduation. There are many brand names for one medicine creating prescription errors. These can be reduced if all physicians prescribe medicines using their generic names.

Although brand names are more memorable or evocative than generic ones and are easier to pronounce but generic drugs are significantly low in cost than their branded equivalents. ${ }^{1,2}$ One reason for this is competition among manufacturers when drugs are no longer protected by patents. Companies incur fewer costs in creating generic drugs as they do not bear the burden of developing the drug and proving its safety and efficacy through clinical trials, since these trials have already been conducted and are therefore able to maintain profitability at a lower 
price. $^{2-4}$ Thus the cost of generic drugs is low and users in many less-prosperous countries can afford them.

Most nations require generic drug manufacturers to prove bioequivalence of their formulation with innovator product. In the United State, generic drugs must be approved by FDA as innovator drugs for which requires bioequivalence of the generic product to be between $80 \%$ to $125 \%$ of that of the innovator product. ${ }^{4-7}$ However this value range is part of statistical calculation, and does not mean that FDA allows generic drugs to differ from the brand name counterpart by up to 25 percent.

Further however to assure quality, safety, and effectiveness, the FDA puts all generic drugs through a review process including review of scientific information about their ingredients and efficacy. FDA conducts approximately 3,500 on-site inspections each year to ensure that generic drug manufacturing plants meets the same high standards as branded drug plant. About half of all generic drugs are manufactured by brand name companies. Pharmaceutical companies make generic copies of their own brands or some other company's brand name drugs and then sell them at a much lower rate without the brand name. Generics are supplied to the government hospitals and dispensaries but only branded drugs are promoted to doctors. Indian pharmaceutical industry is one of the world's largest, most developed industries having distinction of producing high quality generics but at the same time it has been identified as one of the sources of counterfeit medicines by the organisation for economic cooperation and development.

Many unregistered physicians may be familiar with the brand name of drug only but unaware of its generic name and pharmacological profile. ${ }^{5-7}$ Physicians may prefer brand names for prescribing a particular drug for a variety of reasons. The present study was conducted to know the preference of registered medical practitioners towards generic name or brand name and to know the reason for particular preference.

\section{METHODS}

This was a questionnaire based, observational study, carried out among 300 physicians working in state of Punjab in various government and private hospitals from July 2014 to April 2015. The permission was obtained from Institutional Ethics Committee. Questionnaire was filled after fulfilling the inclusion criteria and verifying exclusion criteria as follows:

\section{Inclusion criteria}

- $\quad$ General physician (MBBS)

- $\quad$ Specialist (MD, DNB, MS)

- $\quad$ Super specialist (DM, Mch)

\section{Exclusion criteria}

- Ayurvedic practitioners

- Physician practising other system of medicine homeopathy, unani, etc.

- Unregistered medical practitioner

The questionnaire was evaluated and the responses were recorded in percentages.

\section{RESULTS}

The data was collected from 300 registered medical practitioners of hospitals and teaching institutes in state of Punjab. 276 (92\%) physicians prescribe the drug by brand name and don't allow the pharmacist to substitute the same, rest $24(8 \%)$ prescribe by generic names. Physician did not prescribe by generic name as they feel that it leads to dispensing of substandard products. $234 \quad(78 \%)$ physicians were of the view that generic drugs were less efficacious, $57(19 \%)$ considered these as substandard and $9(3 \%)$ said they had more side effects (Figure 1). 25\% had view that generics were available at less- price due to non-expenditure on their development. Only 66 (22\%) said generics were equally efficacious as their branded counter parts but they did not prescribe by generic names due to fear that it could be substituted by the substandard product by the chemist, as its sole motive to earn maximum profit.

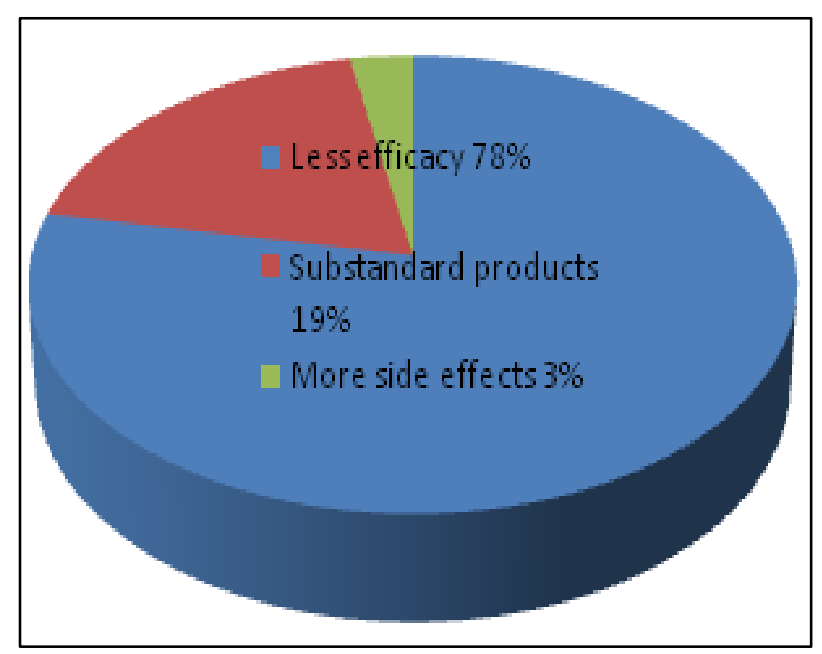

Figure 1: Views about generic drugs.

$249(83 \%)$ doctors consider patient affordability while prescribing however only $180(60 \%)$ of them informed the patient about the cost of the prescribed drug. $30(10 \%)$ responded that health care administration policy and 21 (7\%) said drug company representative effects prescription behaviour pattern. 294 (98\%) said they had never reported substandard quality of drug to higher authorities. 285 (95\%) thought that the patient would not be allowed to choose any brand for a particular drug (Table 1). 
Table 1: Preference pattern and factors influencing prescription of drugs by generic or brand name.

\begin{tabular}{|lll|}
\hline & Yes & No \\
\hline Prescribe by brand name & $276(92 \%)$ & $24(8 \%)$ \\
\hline $\begin{array}{l}\text { Generic drug equally } \\
\text { efficacious to brand drug }\end{array}$ & $66(22 \%)$ & $234(78 \%)$ \\
\hline $\begin{array}{l}\text { Choice of patient to buy } \\
\text { any brand }\end{array}$ & $15(5 \%)$ & $285(95 \%)$ \\
\hline Substitution by chemist & $6(2 \%)$ & $294(98 \%)$ \\
\hline $\begin{array}{l}\text { Consider Patient } \\
\text { affordability }\end{array}$ & $249(83 \%)$ & $51(17 \%)$ \\
\hline $\begin{array}{l}\text { Information regarding cost } \\
\text { of drug to the patient }\end{array}$ & $180(60 \%)$ & $120(40 \%)$ \\
\hline $\begin{array}{l}\text { Reporting of Substandard } \\
\text { products to higher } \\
\text { authorities }\end{array}$ & $6(2) \%$ & $294(98 \%)$ \\
\hline
\end{tabular}

\section{DISCUSSION}

Majority of physicians prescribe drugs by brand name believing it to have better efficacy and reliability. The reason behind non-prescription of drugs by generic name is dispensing of spurious products which are substandard and non-efficacious. The generic drug or generics is defined as "a drug product that is comparable to brand/reference listed drug product in dosage form, strength, route of administration, quality and performance characteristics and intended use." ${ }^{2,3,8}$ It has also been defined as a term referring to any drug marketed under its chemical name without advertising. ${ }^{3,8}$ For a drug to be bioequivalent to its branded counterpart, it must deliver the same amount of the active ingredients in the same time. A generic must not look like the original due to trademark protection. Inactive ingredients, flavours, fillers and dyes may be different from the brand name medication. There is needed to make physicians aware regarding the generic drugs which are identical to or within an acceptable bioequivalent range of the brand name counterpart with respect to pharmacokinetic and pharmacodynamics properties according to the United State Food and Drug Administration (FDA).

Pharmaceutical companies making generic versions of medications are not required to do the research that is needed to create the drug in the first place or put the drug through clinical trials; or set up marketing campaigns for the generic drug. Eliminating these three factors from the cost of manufacturing means that a generic can be sold at a far lower price than the brand-name version but in India generic drugs are being sold at the maximum retail price mentioned on it, which is approximately same or even higher as that of branded drugs. In UK, generic drug pricing is controlled only by the reimbursement price. Beneath this, the price paid by chemists and doctors is determined mainly by the number of licence holders, the sales value of the originator brand and the ease of manufacture. A typical price decay graph will show a 'scalloped' curve, which usually starts out on the day of generic launch at the brand price, and then falls as competition intensifies. After some years, the graph typically flattens out at approximately $20 \%$ of the originator brand price. ${ }^{2,3,8}$ In our country there is no regulation of price of generics and no mention of the drug to be generic that results in paying more for them by the patient. The retailers and the pharmacist charge exorbitant price for generic drugs. Government should have to come up with policy of regulating the MRP of generic drugs and should have to certify these drugs in order to decrease the health care cost. Government has taken initiative to launch Jan aushadi outlets throughout India aimed at providing cheaper, non-branded, essential medicines. This scheme is launched by department of pharmaceuticals, Ministry of chemicals and fertilizers Government of India in which government procures bulk medicines for public health services. In August 2013 BPPI (Bureau of pharma PSUs of India) has provided guidelines to help individual entrepreneurs including unemployed pharmacists/ doctors/Registered medical practitioner in opening of Jan aushadi. A margin of $16 \%$ for JAS on the sale price of JAS is built in the MRP of each drug plus incentives linked to sale of medicine @ $10 \%$ of monthly sales amount subject to ceiling of rupees ten thousand. More of these centres should be opened in all cities. The availability of generic equivalents for brand-name drugs makes it easier for patients with low incomes or no health insurance to get the medications they need.

Incentives given to prescribing doctors by pharmaceutical companies as their marketing strategy also seem to be reason behind brand name prescribing. Government can lay down policies to limit the incentives expenditure Medical Council of India has stepped forward to stop this tradition.

The physicians felt that if they allowed pharmacist to substitute the drug they will never dispense the cheapest brand as their motive is margin only. Government of India through the Central Drug Standards Control Organisation (CDSCO), the country's apex regulator and the National Institute of biological, Noida has embarked on the largest ever survey of spurious and substandard drug formulations. The survey is meant to develop scientific evidence regarding the quality of drugs in Indian market in the wake of fears around their safety.

The availability of spurious and substandard drugs has dent the confidence of the physicians regarding the use of generics at the same time, it's the duty of the physicians to report substandard products to higher authorities if they come across it. There should be a clear cut policy regarding the generics. A certified and legal frame work should be there to ensure sale of these at actual cost. The regulating agencies have to assure the efficacy of these products. The spurious and substandard drugs available in the market have to be checked and strict action should be taken in order to maintain the quality of these products. This will boost the confidence of the physicians in 
prescribing the generic drugs which ultimately lead to decreased health care cost.

\section{Funding: No funding sources}

Conflict of interest: None declared

Ethical approval: The study was approved by the Institutional Ethics Committee

\section{REFERENCES}

1. Hemminki E, Enlund H, Hellevuo K, Laurila R, Turakka H. Trade names and generic names. Problems for prescribing physicians. Scand J Prim Health Care. 1984;2:84-7.

2. Generic drugs, center for drug evaluation and research, U.S. Food and Drug Administration; 2008.

3. Food and Drug Administration, generic drugs: questions and answers". Food and Drug Administration; 2010.

4. Bower AD, Burkett GL. Family physicians and generic drugs: a study of recognition, information sources, prescribing attitudes, and practices. J Fam Pract. 1987;24:612-6.

5. Mathews AW. When a drug maker creates a new pill, Uncle Sam vets name. FDA tries to avoid mix-ups, similar monikers, dupes; Bonviva becomes Boniva. Wall Street J. 2006:1.

6. WHO technical report series no. 937: Annex 7 (pdf) WHO expert committee on specifications for pharmaceutical preparations, fortieth report (WHO technical report series no. 937): Annex 7 Multisource (generic) pharmaceutical products: guidelines on registration requirements to establish interchangeability; 2006.

7. Food and Drug Administration, department of health and human services: Code of Federal Regulations 320 Title 21, Volume 5, Revised as of April 1, 2008 CFR 320 21/5; 2008.

8. Office of generic drugs, center for drug evaluation and research, US food and drug administration, Generic drugs: What you need to know; 2009.

Cite this article as: Kumar R, Bajaj JK, Sood M, Grewal N, Jassal B. To study prescription behaviour of physician in regard to brand and generic name. Int J Basic Clin Pharmacol 2016;5:1327-30. 